\title{
The Securitization of Insurance Liabilities: The View from Zurich
}

\author{
Dieter Wemmer \\ Zurich Financial Services, Mythenquai 2, Zurich 8022, Switzerland. \\ E-mail: dieter.wemmer@zurich.com
}

Insurance-linked securities (ILS) will play an important role in the future. At Zurich Financial Services, ILS have contributed to a better understanding of alternative capital market solutions. They are an essential part of our capital market activities and a key strategic lever. More broadly, the process of securitization has contributed to the recent transformation of the banking industry, and we should ask ourselves whether the banking model ("originate to securitize") could be valid for insurers too. One strength of securitization is that it will open access to non-traditional and seemingly unlimited sources of capital on a multi-year basis and with limited counterparty credit risk. Securitization is also likely to foster a more efficient use of capital. But insufficient data and modeling capacity make it hard to repackage insurance risk for the markets. Additional impediments are the lack of standardization and the industry's reluctance to disclose proprietary underwriting information. Our comparative advantage is underwriting, which appears to make capital market solutions relatively unattractive. At the same time, we should not discount the demand side. ILS constitute an alternative and attractive class of assets. The development of secondary trading platforms will be essential for the ILS market to grow to maturity. We should also ensure that the incentive structure of market participants reflects underlying risks. This could be done within a framework of self-regulation.

The Geneva Papers (2008) 33, 1-6. doi:10.1057/palgrave.gpp.2510161

Keywords: alternative assets; capital market solutions; convergence; insurance-linked securities; securitization

\section{Introduction}

It may appear preposterous to discuss securitization of insurance-linked securities (ILS) at a time of financial market turbulences caused by securitization having seemingly gone astray. But the wheel of innovation cannot be turned back. Securitization is here to stay, and ILS will play an important role in the future. As a cautious forecaster, I am leaving it open, of course, as to when this point will be reached.

Although the market for ILS has been developed to a large extent by reinsurers and investment banks that were in the lead of many ILS transactions, the role of primary insurers has been growing too. For example, Zurich Financial Services (Zurich) has actively made use of reinsurance solutions provided by the capital markets to manage earnings and balance sheet risks. Our experience includes Lanner Re, a side-car structure offered two years ago. Together with our reinsurers, we sponsored two deals 
covering hurricane and earthquake risk (Kamp Re and Lakeside Re). In the U.S., we availed ourselves of regulatory capital relief through an XXX transaction done by our subsidiary Farmers New World Life, and we purchased fully collateralized reinsurance from special-purpose vehicles sponsored by hedge funds and investment banks.

The experience with these transactions has been positive. They contributed to our better understanding of alternative capital market solutions. We will continue to explore these alternative solutions also in the future. They are an important part of our capital market activities and a key strategic lever.

\section{A transformational challenge?}

More broadly, it has not escaped our attention that the process of securitization has contributed to the recent transformation of the banking industry. Over the last 25 years, banks have developed various forms of asset-backed securities (ABS) and sold them to a broad spectrum of market participants. The securitization supported their drive toward an improved balance sheet management. Of course, the litmus test has yet to be passed whether the ensuing slicing and dicing of risk in the form of rather complex derivatives has made the financial markets more efficient and stable. But we can at least acknowledge that the growth of ABS instruments was paralleled by an impressive improvement in the profitability of commercial banks. Not only has the return on equity risen from single to double digits, over the course of the last 25 years, we have also seen a sizeable reduction in the earnings volatility of commercial banks.

Of course, we would be ill advised to copy the securitization model without reflecting on cause and effect. A number of questions come to mind. Was it really securitization? How much did it contribute to the banks' improved performance? And how easily is the model transferable? I happen to believe that our industry is at the threshold of a fundamental transformation, which will include all facets of insurance - production, distribution and capital management. In the context of the latter, we should indeed ask ourselves whether the banking model ("originate to securitize") can be valid also for us. And what really are the consequences if we adopt it?

\section{Still a cumbersome alternative}

These are difficult questions, and I can offer only tentative answers. One of the strengths of securitization is that it would open access to non-traditional and seemingly unlimited sources of capital on a multi-year basis and with limited counterparty credit risk. Thus, securitization has the potential to reduce our exposure to the constraints in reinsurance capacity and the ensuing price fluctuations. These are indeed attractive features and we should be interested in their further development.

On a more systemic level, securitization and the valuation of insurance liabilities by the markets are likely to foster a more efficient use of our capital. I agree with the conclusion of the Group of Thirty that the disciplining effect of the markets could 
promote an even better understanding of insurance risk and its pricing particularly in areas where gaps in cover exist. ${ }^{1}$

At the same time, we should not close our eyes to the fact that insufficient data and modeling capacity make it hard to repackage insurance risk for the markets. Additional impediments are the lack of standardization of underlying risk and our industry's reluctance to disclose proprietary underwriting information. It also appears that market participants have not (yet) developed an appetite for what we are most interested in offering. Their time horizon tends to be short; they are not (yet) interested in long tail risk; and they have begun only recently to show an interest in higher frequency events. Moreover, we should recognize that many technical risks are diversifying rather well on our balance sheets. Our - presumably profitable comparative advantage is in underwriting, which appears to make capital market solutions relatively unattractive.

Our experience with the Kamp Re transaction may illustrate some of these points. The basis was a conventional reinsurance transaction of U.S. windstorm and New Madrid earthquake exposure with Swiss Re transforming the risk for placement in the markets through catastrophe bonds. It closed on August 1, 2005, with a nominal amount of USD 190 millions representing 95 percent of a USD 200 million layer. On August 28, only 4 weeks later, hurricane Katrina struck. The transaction has subsequently satisfied the requirement of a "reduced interest event" by our demonstration that the sum of paid losses plus reserves exceeds the exhaustion point of the coverage. This means that the spread paid to bondholders in excess of LIBOR has been reduced to a nominal amount. But to date no payments have been made by Kamp Re and the bond principle has not been drawn.

In our experience, the claim process under Kamp Re has been complex and cumbersome. Furthermore, timely communication with investors was impaired by certain terms in the transaction. The weaknesses appear to underscore a general perception that ILS are complex, inflexible and difficult to administer, particularly when compared to reinsurance. These are challenges. They must be addressed if insurers want to develop the full potential of securitization.

\section{Room to grow}

In light of these weaknesses, it does not come as a surprise that, despite their promise, capital market alternatives to reinsurance have seen only modest growth since the late 1980s, when securitization started in the U.S. life insurance sector, and the early 1990s, when the first catastrophe bonds were offered in the wake of hurricane Andrew. As of mid-2007, a total of roughly USD 35 billion of life and general insurance risks has been securitized. This volume pales when contrasted to the total of all reinsurance liabilities or the capacity of the global bond market of USD 41.5 trillions.

The market for ILS has, at least in principle, plenty of room to grow. Current uses continue to revolve around a limited range of low-probability/high-severity risks, such

\footnotetext{
${ }^{1}$ Group of Thirty (2006).
} 
as U.S. hurricanes, California earthquakes and peak exposures in life insurance. Convincing answers to the question whether the solutions can be broadened to efficiently deal with more general insurance risk have yet to be found. But we should not underestimate the innovative power of markets. Over the last five years, growth of the ILS market has accelerated significantly. In some cases (U.S. earthquake cover, for example), the price of capital market products has become rather competitive relative to conventional reinsurance. In light of these developments, one practitioner even expects the total volume of ILS instruments to grow to USD 500 billions over the next decade.

While such predictions may seem exuberant, we should not discount the demand side. Investors have learned that ILS constitute an alternative class of assets that are little, or not at all, correlated with the economy and the financial markets and they have turned out to be particularly attractive in an environment characterized by low interest rates. Whereas at the end of the 1990s, insurers and reinsurers held more than half of all outstanding ILS products, their holdings have now declined to less than 10 percent, while banks and hedge funds increased their holdings from 10 percent to 30 percent. During the recent turbulences in the fixed income markets, the markets for catastrophe bonds have remained remarkably calm. In fact, spreads narrowed. They widened only - briefly - in response to the threat to the U.S. Gulf Coast posed by hurricane Dean. Clearly, catastrophe bonds have passed an important stress test. They are an asset class that can provide high and stable returns in an investor's portfolio.

\section{The impact of recent market turbulences}

Before concluding, I would like to reflect on the likely impact of recent financial market turbulences. My thoughts concern transparency and liquidity and - equally important - incentives of market participants.

First to the points on transparency and liquidity. Despite the presence of a sizeable ILS market, we have yet to see a concurrent development of trading platforms despite several attempts to do so. In 1992, the Chicago Board of Trade introduced catastrophe derivatives based on underlying indices, which reflected insurance property losses. They consisted of futures and options written on futures contracts. But trading never took off, and three years later the contracts were replaced by spread options on loss indices provided by Property Claims Services. In 2000, they were also withdrawn, again on account of insufficient interest. A similar endeavor sponsored by the Bermuda Commodities Exchange opened in late 1997. Two years later, it was suspended too and eventually liquidated. Hence, most ILS transactions continue to be private placements and secondary market liquidity has been rather limited.

An essential condition for the sustainability of any market is that it creates transparency and liquidity. One specific lesson of the subprime debacle was to remind us that investors want to know eventually what kind of commitments they are engaged in, and they also want to ensure that there will always be sufficient liquidity to trade and price the products. Where these conditions are not met, investors will withdraw and the market will suffer a setback. Thus, the development of suitable secondary 
trading platforms will be essential for the ILS market to grow to maturity. We should have an interest in liquid secondary markets and consequently contribute to favorable trading environments.

The second lesson concerns incentives affecting the various stages of securitization. The subprime debacle has revealed a broad-based relaxation of due diligence standards. Why bother if the risk can be passed on to another market participant who will pass it on to yet another party before too long? Of course, rating agencies were expected to supply the necessary information, and it is fair to say that their role in evaluating complex financial products was either not clearly defined or simply misunderstood. But the fundamental "principal-agent" problem extends beyond rating agencies. It includes all players in the supply chain of securitization and we should be mindful that investors, in their aggressive search for yield, had also slipped in observing the principles of sound due diligence. The incentive structure of all market participants should be revisited and more appropriate checks and balances should be applied.

This defines a huge challenge for the promotion of ILS. It not only involves the practitioners of our industry, it also extends to other market participants, rating agencies and regulators. Avoiding future crashes requires firm guidelines that can reign in "irrational exuberance" today. Markets need rules and participants must be held accountable. This is perhaps the only hope to dampen excessive volatility.

But we have to be careful not to throw out the baby with the bath water. I am not calling for more and potentially stifling regulation. There is no public policy rationale to protect large institutional investors, which are, and will continue to be, the main holders of ILS instruments. I am rather calling for a framework that promotes high standards of due diligence and sets proper incentives for risk taking.

Such a framework may also include self-regulation. But self-regulation will fail if it is expected to work in an environment of laissez faire, laissez aller. As Keynes observed, capitalism thrives on the animal spirits of entrepreneurs, and that is precisely one reason why markets are subject to regulation - to tame the animal spirits of capitalism and protect the economy from the unintended consequences of exuberance. The recent trend toward deregulation appears to have induced the demise of self-regulation and we should endeavor to reverse the trend. But this is a task I shall leave for others to tackle.

\section{The way forward}

The perhaps more mundane challenges for practitioners are to address the issues that so far have stood in the way of a widespread securitization of insurance liabilities. Steps along the way must include standardization of products and policies. We must have better policy and underwriting documentation to support the improved duediligence mentioned above. This should make ILS instruments attractive to a wider investor base. Only a growing number of buyers will eventually facilitate an efficient market deepening. We should also work hard with our counterparts in the market to develop solutions for the securitization of long-tail risks. 
Finally, we must continue our dialogue with rating agencies and regulators with a view to obtain regulatory capital relief on the basis of securitization. The implementation of risk-based capital models in connection with the introduction of Solvency II in the EU and the Swiss Solvency Test in Switzerland is likely to contribute to a better understanding of different risks and their respective capital requirements. In this perspective, an evolving regulatory practice that also reflects the benefits of securitization may provide the pivotal stimulus to allow for the broader utilization of ILS in Europe.

These few points by no means exhaust the list of obstacles to overcome. For securitization to succeed, the ILS market must achieve a critical size. It requires a flow of securities with enough desirable features to attract a growing number of investors. This is in some way a circular "chicken and egg" problem. But we cannot benefit from the expected favorable features of a deep, liquid and efficient market if we are not prepared to make an investment in the development of this market. This may require transformational change. That said, it would be audacious to expect that securitization will drive our industry's transformation in the same way it has influenced the banking industry. But it will undoubtedly broaden our options for capital and balance sheet management. For this reason, I expect the securitization of insurance liabilities to impact our industry in a meaningful way.

\title{
Reference
}

Group of Thirty (2006) Reinsurance and International Financial Markets, Washington, DC: Group of Thirty.

\begin{abstract}
About the Author
Dieter Wemmer is a member of the Group Executive Committee and Chief Financial Officer of Zurich Financial Services. He joined Zurich Re (Cologne) in 1986 as pricing actuary life reinsurance. In 1996, he was seconded to the Corporate Center in Zurich as project manager with the responsibility of implementation of IAS/US GAAP. From 1999 until May 2003, Mr. Wemmer was Head of Mergers and Acquisitions with additional responsibility of Capital Management and General and Life Actuarial from 2002. In 2003, he was promoted to Chief Operating Officer Europe General Insurance. In November 2004, Dieter Wemmer joined the Group Executive Committee as CEO Europe General Insurance. In March 2007, he was appointed to his current position. Mr. Wemmer holds a Ph.D. in mathematics from the University of Cologne.
\end{abstract}

